\title{
The Difference Between Actual and Prescribed Weight Bearing of Total Hip Patients With a Trochanteric Osteotomy: Long-Term Vertical Force Measurements Inside and Outside the Hospital
}

\author{
Henri L. Hurkmans, PhD, Johannes B. Bussmann, PhD, Ruud W. Selles, PhD, Eric Benda, PT, \\ Henk J. Stam, MD, PhD, Jan A. Verhaar, MD, PhD
}

ABSTRACT. Hurkmans HL, Bussmann JB, Selles RW, Benda E, Stam HJ, Verhaar JA. The difference between actual and prescribed weight bearing of total hip patients with a trochanteric osteotomy: long-term vertical force measurements inside and outside the hospital. Arch Phys Med Rehabil 2007; $88: 200-6$.

Objective: To determine whether patients load the operated leg at a prescribed weight-bearing target load during postoperative recovery.

Design: A descriptive prospective study.

Setting: Orthopedic clinic and patients' homes.

Participants: Fifty patients who had undergone total hip arthroplasty (THA) with trochanteric osteotomy.

Intervention: Patients were verbally instructed by a physical therapist to perform partial weight bearing at a $10 \%$ body weight $(\mathrm{BW})$ target load $(\mathrm{n}=33)$ or at a $50 \% \mathrm{BW}$ target load $(\mathrm{n}=17)$.

Main Outcome Measures: Mean peak load (\%BW) and percentage of patients and mean percentage of steps below, equal to, and above the target load. Weight bearing was measured when patients walked with (condition 1) and without (condition 2) a physical therapist in the hospital and walked at home (condition 3 ).

Results: The mean peak load was significantly higher than the target in the $10 \% \mathrm{BW}$ group for all 3 conditions (condition 1, $19.2 \% \mathrm{BW}$; condition 2, 20.0\% BW; condition 3, 26.8\% $\mathrm{BW})$. In the $50 \% \mathrm{BW}$ group, the mean peak load was significantly lower than the target in conditions $1(28.1 \% \mathrm{BW})$ and 2 $(32.5 \% \mathrm{BW})$. No significant difference in weight bearing was found when walking with or without a physical therapist (change in $10 \% \mathrm{BW},-0.1 \% \mathrm{BW}$; change in $50 \% \mathrm{BW}$, $-3.17 \% \mathrm{BW})$. At home, the mean peak load was significantly larger compared with walking without a physical therapist in the hospital (change in $10 \% \mathrm{BW},-7.0 \% \mathrm{BW}$; change in $50 \%$ BW, $-11.5 \%$ BW).

Conclusions: Partial weight bearing at a specific target load was not achieved by patients with a THA when given verbal instructions. Especially when using a low target load and when walking at home with no supervision of a physical therapist,

From the Departments of Physical Therapy (Hurkmans, Benda), Rehabilitation Medicine (Bussmann, Selles, Stam), and Orthopedic Surgery (Verhaar), Erasmus MC-University Medical Center, Rotterdam, The Netherlands.

No commercial party having a direct financial interest in the results of the research supporting this article has or will confer a benefit upon the author(s) or upon any organization with which the author(s) is/are associated.

Reprint requests to Henri L. Hurkmans, PhD, Dept of Physical Therapy, Erasmus MC-University Medical Center Rotterdam, Dr. Molewaterplein 40, 3015 GD Rotterdam, The Netherlands, e-mail: h.hurkmans@erasmusmc.nl.

0003-9993/07/8802-10732\$32.00/0

doi:10.1016/j.apmr.2006.11.005 patients loaded the operated leg higher and more frequently above the target load. Other training methods (eg, biofeedback) have to be evaluated to use as training tools for partial weight bearing at specific target loads.

Key Words: Arthroplasty, replacement, hip; Physical therapy techniques; Rehabilitation; Weight bearing.

(C) 2007 by the American Congress of Rehabilitation Medicine and the American Academy of Physical Medicine and Rehabilitation

$\mathbf{P}$ ARTIAL WEIGHT BEARING (PWB) is commonly instructed during the rehabilitation of patients with fractures, osteotomies, amputations, or arthroplasties of the lower extremity. ${ }^{1-10}$ For patients with a total hip arthroplasty (THA) and a trochanteric osteotomy, it is important to restrict the activation of the hip abductors to avoid nonunion of the trochanter fragment, which may lead to functional disability. ${ }^{1-16} \mathrm{Al}-$ though the relationship between the load under the foot and the load at the hip is complex, the conventional therapy is to restrict weight bearing. The maximum amount of weight bearing or target load is prescribed by the treating surgeon and given in percentage body weight (BW) or in kilogram load. The goal of PWB training given by the physical therapist is to ensure that the patient loads the operated leg at the prescribed target load.

Factors that may influence the patient's weight-bearing performance are the absence of the physical therapist, the setting (hospital or patient's home), and time after surgery. At the start of rehabilitation, the patient walks with the physical therapist in the hospital and receives instructions and feedback from the physical therapist. At a certain point during rehabilitation in the hospital, the physical therapist decides that the patient is able to perform PWB unsupervised. Although the results of commonly used instruction strategies are reported to be poor, ${ }^{8,17}$ unsupervised walking without verbal feedback from the physical therapist could probably lead to higher limb loading than when walking with a physical therapist. Higher limb loading is also more likely to occur at the patient's home compared with the more controlled clinical setting. Nowadays, the patient recovers for several weeks at home (or in a nursing home), which is longer than the short hospital stay of 5 to 7 days. At home, the patient performs daily activities without help or supervision from a physical therapist and probably does more things alone, which may distract him/her, leading to inefficient handling of the walking aid. ${ }^{18}$ Also, the home environment differs from the hospital environment, which may influence a patient's gait and, therefore, the loading of the operated leg. Because patients generally feel more confident and have less pain several weeks after surgery, they could load the limb above the prescribed target load. Additionally, because patients feel more confident 
they could become more active, thus increasing the risk of loading the limb above the prescribed target load.

Another factor that may influence the patient's weight-bearing performance is the target load prescribed by the surgeon. Studies have shown that lower target loads $(10-15 \mathrm{~kg}, 10 \%-30 \% \mathrm{BW})$ resulted in larger differences between prescribed and actual weight bearing than higher target loads $(50 \% \mathrm{BW})$. $^{5,19-21}$

To gain insight into how much the patient really loads the operated leg during postoperative recovery, long-term weightbearing measurements have to be performed during the patient's stay in the hospital and at the patient's home, instead of short-term gait analyses in a laboratory. In addition, performing measurements over several hours enables us to obtain average and extreme peak loads from routine daily activities. To perform these kinds of measurements, we previously adapted and validated an insole pressure system. ${ }^{22,23}$

The present study aimed to evaluate whether patients with a THA and trochanteric osteotomy unload their operated leg at a prescribed target load after verbal instructions from a physical therapist by comparing the target load with the actual load, which was measured by a valid and reliable insole pressure system. Specifically, we wanted to know what the difference is between the actual load and 2 target loads (10\% and $50 \%$ of BW) in 3 conditions: (1) in the hospital in the presence of a physical therapist, (2) in the hospital without the presence of a physical therapist, and (3) at the patient's home 2 weeks after discharge.

\section{METHODS}

\section{Patient Population}

Between August 2002 and October 2004, 145 consecutive patients received a primary unilateral THA with trochanteric osteotomy for the treatment of osteoarthritis of the hip at the orthopedic departments of 2 hospitals participating in this study. All patients between the age of 40 and 80 years and from whom a written informed consent was obtained were included in the study. Exclusion criteria were: medical conditions or social problems whereby patients could not perform or could not be instructed to perform PWB (eg, Parkinson's disease, epilepsy, alcoholism); postoperative bed rest for more than 3 weeks; foot orthosis; foot deformities that needed special footwear; and a shoe size (European) smaller than 36 or larger than 45. This study was approved by the Erasmus MC-University Medical Center and the Ruwaard van Putten Hospital Institutional Review Boards.

\section{Protocol}

The patients were instructed by a physical therapist to perform PWB with a walker or elbow crutches (3-point gait ${ }^{15}$ ) depending on the walking ability of the patient. PWB training was standardized that only verbal instructions and verbal feedback were given during and/or after PWB, without the use of other training methods or equipment (eg, a bathroom scale or feedback device). The training was performed by 2 to 3 physical therapists in each hospital, which have more than 5 years of experience with PWB training. The patients were generally instructed with a $10 \% \mathrm{BW}$ target load in 1 hospital and with a $50 \% \mathrm{BW}$ target load in the other participating hospital because of different opinions of the operating surgeons on optimal weight bearing.

Weight bearing was measured with the Pedar Mobile system, ${ }^{\text {a }}$ which was validated to measure the vertical force during walking over a long-term period. ${ }^{22}$ The Pedar Mobile system is a portable insole pressure device with matrix insoles (thick- ness, $2 \mathrm{~mm}$ ). Each insole contains 99 capacitive sensors. Before each measurement, the Pedar insoles were calibrated by using the Trublu calibration device ${ }^{\mathrm{a}}$ and a GDH 14AN digital manometer. ${ }^{\mathrm{b}}$ The pressure loads applied were 4,7 , and 10 to $60 \mathrm{~N} / \mathrm{cm}^{2}$ with intervals of $5 \mathrm{~N} / \mathrm{cm}^{2}$. The Pedar system was placed in a custom vest together with a custom battery unit, consisting of 2 batteries (Sony NP750 Li-ion), which was worn by the patient (fig 1). An electronic device with an accelerometer was made to automatically start and stop the Pedar system so that data were recorded only when the patient was standing or walking. The accelerometer was fixated with adhesive tape on approximately the middle front part of the contralateral thigh. The Pedar Mobile system was turned on 1 hour in advance (acclimatization period), and zero settings were done at baseline and 1 hour. $^{22}$ Data collection started after the second zero setting. The weight-bearing measurements were performed on day $7 \pm 2$ postoperatively in the hospital when the patient walked with a physical therapist (condition 1) or walked unsupervised (condition 2) and on day $21 \pm 5$ postoperatively at the patient's home (or in a nursing home) 2 weeks after discharge (condition 3 ). Weight-bearing data during walking were collected over a period of 5 hours (from $\pm 11: 00$ AM to $\pm 4: 00$ PM) at a sample frequency of $50 \mathrm{~Hz}$.

\section{Data Analysis}

Pedar-m Expert version 8.2 software $^{\mathrm{a}}$ was used to calculate the vertical force data from the Pedar system. Then, all Pedar data were imported in a custom Matlab program ${ }^{c}$ and were filtered by using a low-pass Butterworth filter with a cutoff frequency of $40 \mathrm{~Hz}$. The Matlab program was used to select the walking data within the data files and to correct the walking data for offset drift. ${ }^{22}$ For each step, the maximum peak load was determined. From these maximum peak loads, the following variables were calculated for the 2 target loads (10\% and $50 \% \mathrm{BW}$ ) and for each of the 3 conditions: the mean peak load $(\% \mathrm{BW}) \pm$ standard deviation; peak load variance within and between patients; the total number of steps; and the number and percentage of steps below the target load, equal to the target load, and above the target load. Based on the opinion of the orthopedic surgeons at our university hospital, we arbitrarily defined "below the target" as less than $5 \% \mathrm{BW}$ for the $10 \%$ target load and less than $40 \%$ BW for the $50 \%$ target load and "above the target" as more than $20 \% \mathrm{BW}$ for the $10 \%$ target load and more than $60 \% \mathrm{BW}$ for the $50 \%$ target load. The remaining category was defined as "equal to the target."

One-sample $t$ tests were used to compare the mean peak loads at conditions 1, 2, and 3 with the target load. Paired $t$ tests or $t$ tests were used to compare condition 1 with 2 and condition 2 with 3 for the mean peak load and the percentage of steps below, equal, and above the target load. Correlations between the dependent and the patient variables were determined with Pearson correlation tests. For each test, the level of significance was set at $P$ less than .05. All statistical analyses were performed with SPSS ${ }^{\mathrm{d}}$ for Windows.

\section{RESULTS}

\section{Patient Characteristics}

Fifty patients participated in the study of which 33 patients performed PWB with a target load of $10 \% \mathrm{BW}$ and 17 patients with a target load of $50 \% \mathrm{BW}$ (fig 2). Patient characteristics are presented in table 1 . Age was significantly higher $\left(t_{48}=2.3\right.$, $P=.026)$ and body weight was significantly lower $\left(t_{48}=-1.2\right.$, $P=.023)$ in the $10 \%$ target group compared with the $50 \%$ target group. When looking at men and women separately, these 


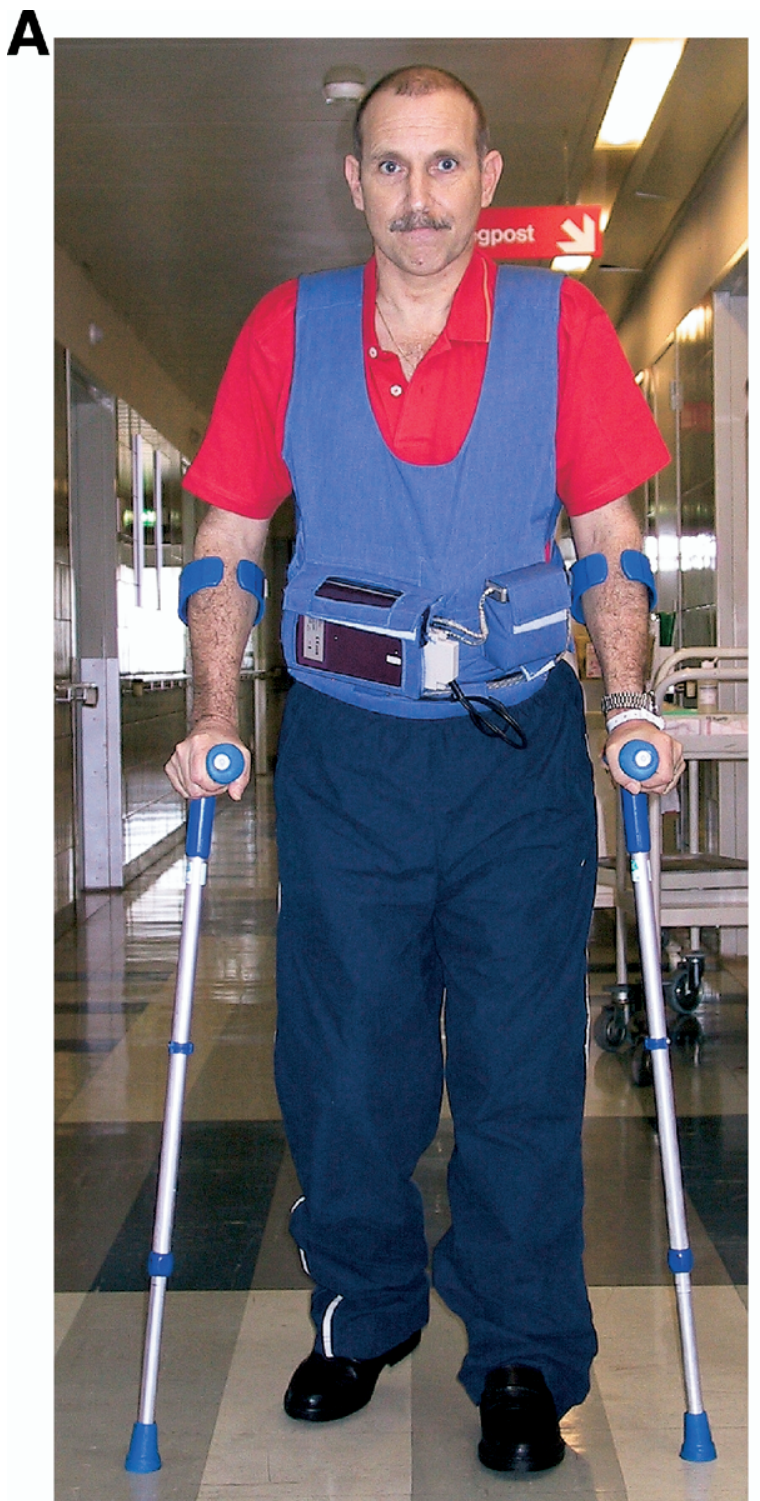

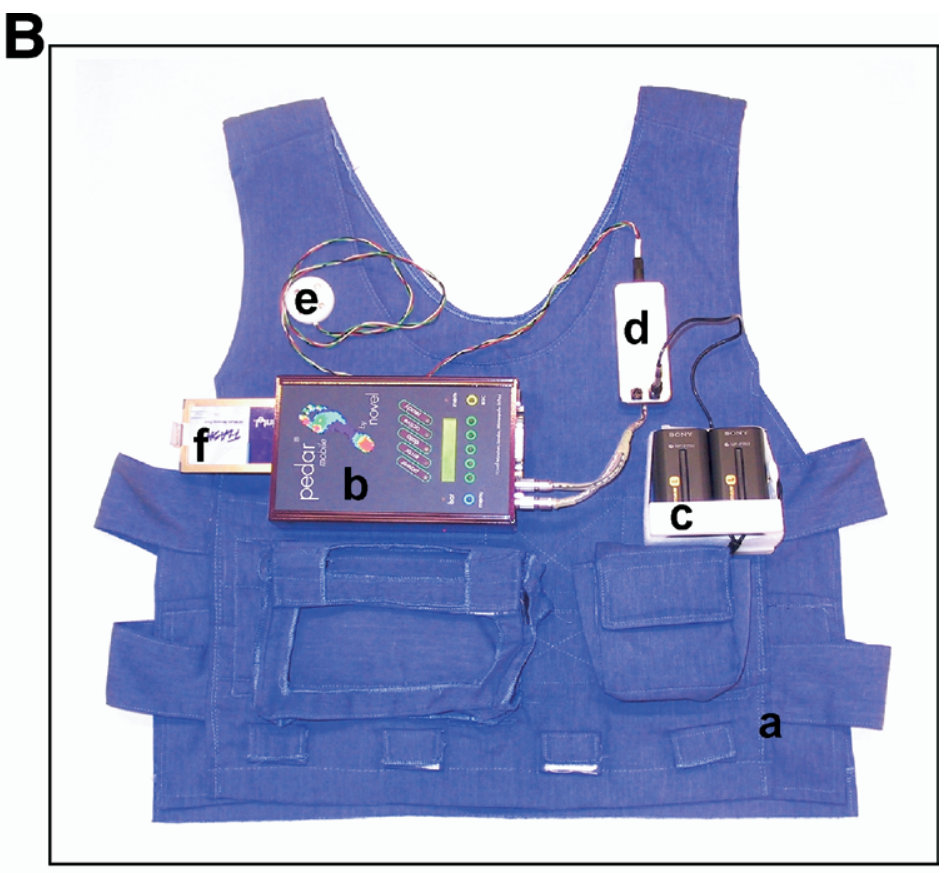

Fig 1. (A) The Pedar system with a custom battery unit placed in a custom vest worn by a patient. The accelerometer is connected to the Pedar system and fixated on the middle front part of the contralateral thigh. (B) Details for the Pedar system. Legend: a, custom vest; $b$, Pedar box; c, battery unit; d, electronic device; e, accelerometer; f, $40 \mathrm{Mb}$ flash card. factors did not differ significantly between the 2 target groups. The $10 \%$ target group had significantly more women $\left(\chi_{33}^{2}\right.$ test $\left.=11.8 P=.001\right)$, but not significantly fewer men than the $50 \%$ target group $\left(\chi_{14}^{2}\right.$ test $\left.=1.0 P=.317\right)$. Age and body weight of the patient did not correlate in the $10 \% \mathrm{BW}$ target group with the mean peak load and did not correlate with the percentage steps below, equal to, and above the target load in all 3 conditions. For the $50 \%$ target load in condition 1, a positive correlation was found between age and the percentage steps equal the target load $(r=.62, P=.042)$ and between body weight and percentage steps above the target load $(r=.73$, $P=.01)$. For condition 2, a negative correlation was found between age and percentage steps below the target load $(r=-.69, P=.02)$. Because of mostly logistic reasons, not all patients were measured at each condition. From the 33 patients with the $10 \% \mathrm{BW}$ target load, respectively, 25, 26, and 26 patients and from the 17 patients with the $50 \%$ BW target load, respectively, 11,11 , and 16 patients were measured for conditions 1,2 , and 3 , respectively. To assess the amount of weight bearing in the $10 \% \mathrm{BW}$ and $50 \% \mathrm{BW}$ target load group for conditions 1,2, and 3 during a long-term period, a total of 1752,3029 , and 10,258 steps, respectively, and a total of 1120 , 1788 , and 7498 steps were evaluated.

\section{PWB With Supervision}

When patients walked with the physical therapist, $64 \%$ patients had a mean peak load equal to and $32 \%$ of the patients had a mean peak load above the $10 \%$ BW prescribed target load (table 2). The mean peak load $(19.2 \% \mathrm{BW})$ was significantly higher than the target load $\left(t_{24}=4.0, P=.001\right)$. Fifty percent of the steps were equal to the prescribed target load. The distribution of the peak loads showed a large variety in weight bearing, with peak loads up to $55 \%$ to $60 \%$ BW (fig 3). The patients' within-variance and between-variance weight bearing was $22.1 \%$ and $2.2 \% \mathrm{BW}$, respectively.

For the $50 \%$ target load, the number of patients with a mean peak load equal and above the prescribed target load was $36.4 \%$ and $0 \%$, respectively. The mean peak load was signif- 


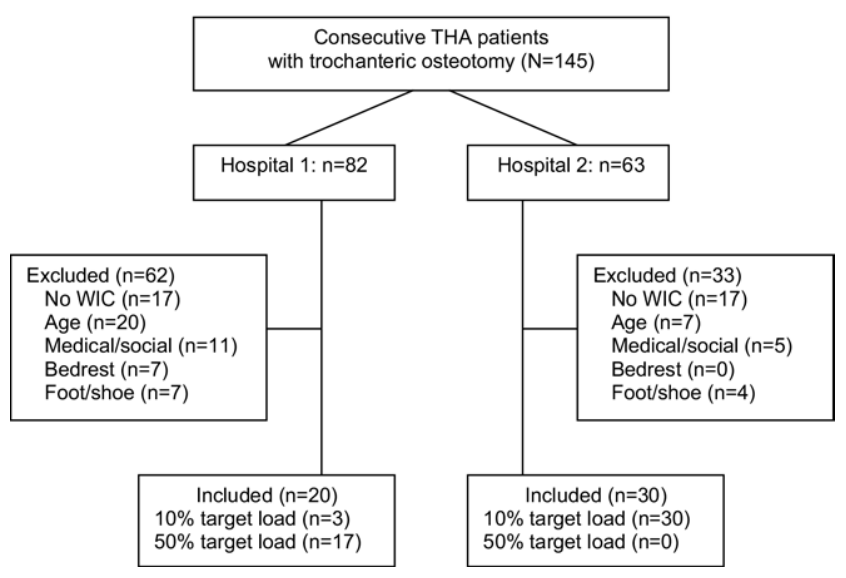

Fig 2. Flow chart of patient inclusion and exclusion in the study. Abbreviation: WIC, written informed consent.

icantly lower $(28.1 \% \mathrm{BW})$ than the target load $\left(t_{10}=-4.5\right.$, $P=.001)$. Sixty-six percent of the steps were below the target load. The distribution of the peak loads showed loads up to $65 \%$ to $70 \% \mathrm{BW}$ (fig 4), and patients' within-variance and between-variance weight bearing was $46.2 \%$ and $5.1 \% \mathrm{BW}$, respectively.

\section{PWB Without Supervision}

When walking without supervision in the hospital the percentage of patients with a mean peak load above the target load was increased with $9 \%$ to $10 \%$ in the $10 \% \mathrm{BW}$ target load group. The mean peak load $(20.0 \% \mathrm{BW})$ was again significantly higher than the target load $\left(t_{25}=5.1, P=.000\right)$. The percentage of steps equal the target load was $31.6 \%$. As in condition 1 , the distribution of the peak loads showed again a large variety in weight bearing, with peak loads up to $55 \%$ to $60 \%$ (see fig 3). The weight-bearing variance within and between patients was $33.6 \%$ and $1.9 \% \mathrm{BW}$, respectively.

Also within the $50 \%$ target group, an increase of $9 \%$ to $10 \%$ was found in the percentage of patients with the mean peak load above the target load. Similar to condition 1, the mean peak load was significantly lower $(32.5 \% \mathrm{BW})$ than the target load $\left(t_{10}=-3.2, P=.009\right)$. Without supervision, peak loads were measured up to $90 \%$ to $95 \% \mathrm{BW}$ (see fig 4). The weightbearing variance within and between patients was $54.8 \%$ and $5.7 \%$ BW, respectively.

\section{PWB at Home 2 Weeks After Discharge}

At home, 2 weeks after discharge, the percentage of patients with a mean peak load above the $10 \%$ target load was increased to $69.2 \%$. The mean peak load $(26.8 \% \mathrm{BW})$ was significantly higher than the prescribed target $\left(t_{25}=6.7, P=.000\right)$. The percentage of steps above the target load was increased to $63.6 \%$. Peak loads were measured up to $70 \%$ to $75 \%$ BW (see fig 3). The weight-bearing variance within and between patients was $44.9 \%$ and $2.6 \% \mathrm{BW}$, respectively.

In the $50 \% \mathrm{BW}$ target load group, the mean peak load $(43.3 \% \mathrm{BW})$ did not differ significantly from the target load $\left(t_{15}=-1.7, P=.117\right)$, and the percentage of steps above the target load was $17.4 \%$. However, peak loads were measured up to $90 \%$ to $95 \% \mathrm{BW}$ (see fig 4). The weight-bearing variance within and between patients was $106.1 \%$ and $5.8 \% \mathrm{BW}$, respectively.

\section{Comparing PWB Conditions}

When comparing condition 1 (in hospital with the physical therapist) with condition 2 (in hospital without the physical therapist), no significant difference was found in the mean peak load in both target load groups (table 3 ). In condition 3 (at home), the mean peak load was significantly higher than during condition 2 in both target load groups $(10 \% \mathrm{BW}$ target, $t_{22}=-2.4, P=.025 ; 50 \% \mathrm{BW}$ target, $\left.t_{9}=-2.6, P=.027\right)$. No significant differences were found between conditions 1 and 2 for the percentage of steps above the target load. When patients walked at home at a $10 \% \mathrm{BW}$ target load, $17.2 \%$ more steps were above the target load than during unsupervised walking in the hospital, but this difference was not significant $\left(t_{22}=-1.9\right.$, $P=.074)$. With a $50 \% \mathrm{BW}$ target load, $9.4 \%$ more steps $\left(t_{9}=-2.4, P=.043\right)$ were above the instructed target load when patients walked at home. At home, patients walked significantly more during the 5-hour data-collection period than during unsupervised walking in the hospital $(10 \% \mathrm{BW}$ target, $t_{22}=-4.9, P=000 ; 50 \% \mathrm{BW}$ target, $\left.t_{9}=-2.4, P=.039\right)$, whereas in the hospital no difference was found in the number of steps (condition 1 vs condition 2).

\section{DISCUSSION}

The present study evaluated PWB of patients with a THA and trochanteric osteotomy during their postoperative recovery by measuring the actual load during walking with a validated insole pressure system over a 5-hour period in the hospital and at home and comparing it with 2 instructed target loads in 3 conditions.

In this study, we found that $55 \%$ of the patients did not load their operated leg at the prescribed target load during their recovery when walking with (condition 1 ) or without (condition 2) supervision of a physical therapist in the hospital and when walking at home (condition 3 ). The results were even worse when looking at the percentage of steps (61\%) taken by the patients that were unequal to the target loads. Previous patient studies on PWB also found that a large percentage of steps $(40 \%-80 \%)$ of the patients were above the target load

Table 1: Age and Body Weight of the Patients in the 10\% and $\mathbf{5 0} \%$ BW Target Load Group, and the Mean Differences With Test Values

\begin{tabular}{|c|c|c|c|}
\hline Characteristics & $\begin{array}{c}10 \% \text { BW } \\
\text { Target Load }\end{array}$ & $\begin{array}{c}50 \% \text { BW } \\
\text { Target Load }\end{array}$ & $\begin{array}{l}10 \% \text { to } 50 \% \mathrm{BW} \\
\text { Target Load }\end{array}$ \\
\hline Patients & 33 & 17 & NA \\
\hline Age (y) & $64.1 \pm 8.7$ & $57.8 \pm 10.0$ & $\begin{array}{c}6.2 \pm 2.7 \\
t_{48}=2.3, P=.026\end{array}$ \\
\hline $\mathrm{BW}(\mathrm{kg})$ & $75.4 \pm 9.1$ & $79.7 \pm 17.7$ & $\begin{array}{c}-4.3 \pm 3.8 \\
t_{48}=-1.2, P=.023\end{array}$ \\
\hline Men & 6 & 10 & $\begin{array}{c}-4 \\
\chi_{14}^{2}=1.0, P=.317\end{array}$ \\
\hline Age (y) & $58.0 \pm 7.5$ & $53.1 \pm 6.6$ & $\begin{array}{c}4.9 \pm 3.6 \\
t_{14}=1.4, P=.195\end{array}$ \\
\hline BW $(\mathrm{kg})$ & $79.0 \pm 4.1$ & $87.5 \pm 17.2$ & $\begin{array}{c}-8.5 \pm 5.7 \\
t_{14}=-1.5, P=.163\end{array}$ \\
\hline Women & 27 & 7 & $\begin{array}{c}20 \\
\chi_{33}^{2}=11.8, P=.001\end{array}$ \\
\hline Age (y) & $65.4 \pm 8.4$ & $64.6 \pm 10.4$ & $\begin{array}{c}0.84 \pm 3.7 \\
t_{32}=0.2, P=.825\end{array}$ \\
\hline BW (kg) & $74.6 \pm 9.6$ & $68.7 \pm 12.3$ & $\begin{array}{c}5.9 \pm 4.4 \\
t_{32}=1.4, P=.183\end{array}$ \\
\hline
\end{tabular}

NOTE. Values are $\mathrm{n}$ or mean \pm standard deviation (SD). Abbreviation: NA, not applicable. 
Table 2: PWB Data of the Patients During Condition 1, 2, and 3 With a $10 \%$ BW and $50 \%$ BW Target Load

\begin{tabular}{|c|c|c|c|c|c|c|c|c|c|c|}
\hline $\begin{array}{c}\text { Condition } \\
\text { (n) }\end{array}$ & $\begin{array}{c}\mathrm{TL} \\
(\% \mathrm{BW})\end{array}$ & $\begin{array}{l}\text { Patients } \\
\text { (n) }\end{array}$ & $\begin{array}{c}\text { MPL } \\
(\% \text { BW) }\end{array}$ & $\begin{array}{l}\text { All Steps } \\
\text { (n) }\end{array}$ & $\begin{array}{c}\mathrm{MPL}<\mathrm{TL} \\
(\% \text { patients) }\end{array}$ & $\begin{array}{c}\mathrm{MPL}=\mathrm{TL} \\
\text { (\% patients) }\end{array}$ & $\begin{array}{c}\mathrm{MPL}>\mathrm{TL} \\
\text { (\% patients) }\end{array}$ & $\begin{array}{c}\text { Steps }<\mathrm{TL} \\
(\%)\end{array}$ & $\begin{array}{c}\text { Steps }=\text { TL } \\
(\%)\end{array}$ & $\begin{array}{c}\text { Steps }>\text { TL } \\
(\%)\end{array}$ \\
\hline \multirow[t]{2}{*}{1} & 10 & 25 & $19.2 \pm 11.4$ & $70.1 \pm 39.7$ & 4.0 & 64.0 & 32.0 & $11.4 \pm 20.5$ & $50.1 \pm 34.4$ & $38.5 \pm 39.7$ \\
\hline & 50 & 11 & $28.1 \pm 16.0$ & $101.8 \pm 58.9$ & 63.6 & 36.4 & 0 & $66.1 \pm 40.1$ & $31.6 \pm 37.3$ & $2.3 \pm 7.7$ \\
\hline \multirow[t]{2}{*}{2} & 10 & 26 & $20.0 \pm 9.8$ & $116.5 \pm 79.5$ & 3.9 & 53.8 & 42.3 & $9.7 \pm 20.8$ & $43.8 \pm 30.9$ & $46.5 \pm 36.0$ \\
\hline & 50 & 11 & $32.5 \pm 17.9$ & $162.5 \pm 113.1$ & 63.6 & 27.3 & 9.1 & $63.3 \pm 42.5$ & $27.8 \pm 35.8$ & $8.9 \pm 25.7$ \\
\hline \multirow[t]{2}{*}{3} & 10 & 26 & $26.8 \pm 12.8$ & $394.5 \pm 251.4$ & 0 & 30.8 & 69.2 & $3.2 \pm 5.0$ & $33.2 \pm 34.5$ & $63.6 \pm 38.3$ \\
\hline & 50 & 16 & $43.3 \pm 15.9$ & $486.6 \pm 378.6$ & 37.5 & 56.3 & 6.2 & $35.4 \pm 35.9$ & $47.2 \pm 29.0$ & $17.4 \pm 23.4$ \\
\hline Overall & & & & & $28.8 \pm 30.2$ & $44.8 \pm 15.2$ & $26.5 \pm 26.5$ & $31.5 \pm 27.9$ & $39.1 \pm 9.2$ & $29.6 \pm 23.9$ \\
\hline
\end{tabular}

NOTE. Values are $n$, percentage, or mean \pm SD. Body weight ranges: $10 \%$ target load: "below target $(<\mathrm{TL})$ " $=0 \%-5 \%$ BW; "equal to target $(=\mathrm{TL}) "=5 \%-20 \%$ BW; "above target $(>\mathrm{TL}) "=20 \%-100 \%$ BW; $50 \%$ target load: " $<\mathrm{TL} "=0 \%-40 \%$ BW; " $=\mathrm{TL} "=40 \%-60 \%$ BW; ">TL" $=60 \%-100 \%$ BW.

Abbreviations: MPL, mean peak load; TL, target load.

when using either verbal instructions and observation and/or the hand-under-the-foot method and/or a bathroom scale. ${ }^{1,5,7,8,17}$ This indicates that the commonly used methods are inadequate to obtain the prescribed target load. However, our data also showed that PWB seemed to be determined by environment and time after discharge (hospital vs home) and by the prescribed target load. So, when the clinical goal is not to load the operated leg above the target load then verbal instructions seemed to be sufficient for PWB in the hospital at a 50\% BW target load.

Although observation with verbal feedback is a subjective method to control weight bearing, we expected higher limb loads compared with the situation in which the patients walked in the hospital without feedback. However, no significant differences were found between the mean peak load and the percentage steps above the target load of conditions 1 and 2 (see table 3). This would indicate that the patients learned to limit the load on their leg at a certain level when trained by a physical therapist, although this was not the instructed load. Weight-bearing training was done by giving verbal feedback after performing PWB for a few steps. Winstein et $\mathrm{al}^{24}$ concluded that this "postresponse feedback" was effective for learning a PWB skill, but that concurrent feedback (eg, audio feedback during the weight performance) is needed for immediate performance. Another aspect that could explain the similar weight bearing in both conditions is the postoperative pain,

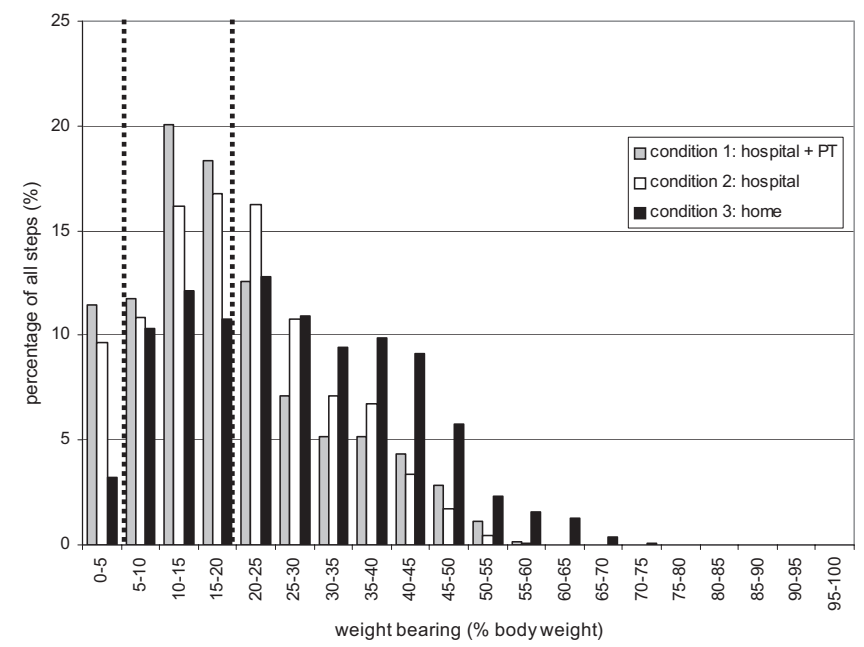

Fig 3. Distribution of the peak forces for the 3 conditions with the target load set at $10 \% \mathrm{BW}$. which may have led the patients to be more cautious in placing the foot on the ground. ${ }^{25}$

At home, the patients loaded their operated leg significantly higher than during unsupervised PWB in the hospital. A reason for this could be that the patients might be more confident and/or may have less pain. These factors might have contributed to the significantly greater number of steps measured at home, which also could increase the risk of incorrect loading the leg. In addition, when a patient walks more the patient could also become fatigued as walking with walking aids is physically demanding ${ }^{26-28}$ and, consequently, load the leg more than the prescribed target load. Also, the patients' compliance with weight-bearing instructions could influence the loading of the operated leg at home. At the patient's home, we occasionally observed that patients used only 1 crutch or did not use the walking aids at all, for example, when opening the front door or while making coffee. Several patients stated that they sometimes forgot to use the walking aid when standing up. Unfortunately, we were not able to match the load data with these events.

We found that, with a low prescribed target load $(10 \% \mathrm{BW})$, a large number of steps were above the target load. This is in line with previous studies on PWB that also found relatively less accuracy when a low target load was used. ${ }^{7,20,21}$ It is obvious that when the patient has to place less weight on the

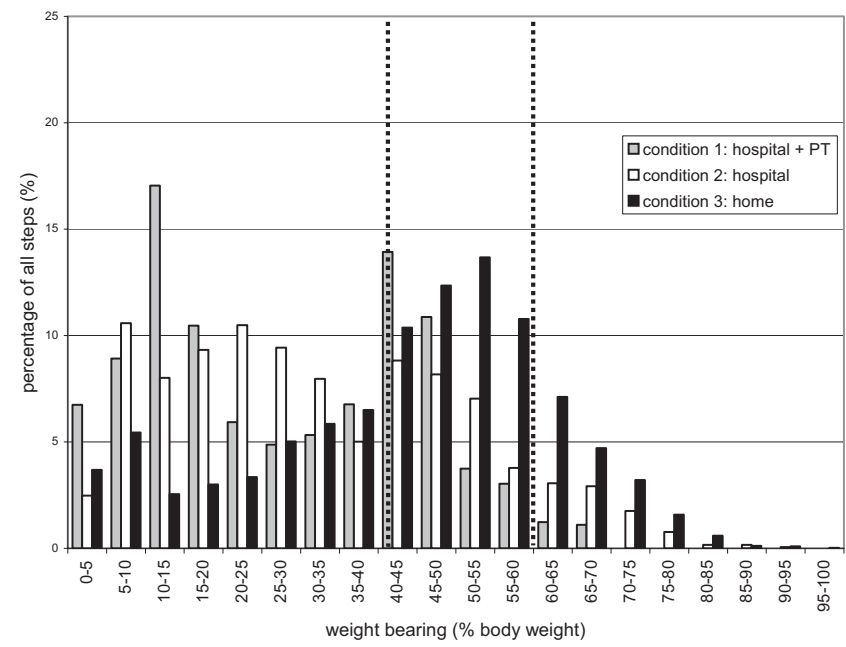

Fig 4. Distribution of the peak forces for the 3 conditions with the target load set at $\mathbf{5 0 \%} \mathrm{BW}$. 
Table 3: Comparison of the PWB Outcome Measures Between Conditions 1 and 2 and Conditions 2 and 3 for the $10 \%$ BW and $50 \%$ BW Target Load

\begin{tabular}{|c|c|c|c|c|c|}
\hline \multicolumn{6}{|c|}{$10 \%$ BW target load } \\
\hline Patients (n) & Conditions ( $\mathrm{n}$ ) & $\begin{array}{c}\Delta \text { Mean Peak Load } \\
(\% \text { BW })\end{array}$ & $\Delta$ Steps $<$ TL $(\%)$ & $\Delta$ Steps $=$ TL $(\%)$ & $\Delta$ Steps $>$ TL $(\%)$ \\
\hline \multirow[t]{3}{*}{20} & 1 and 2 & -0.1 & -1.6 & 3.5 & -1.8 \\
\hline & & $P=.869$ & $P=.526$ & $P=.397$ & $P=.633$ \\
\hline & & $t_{19}=0.2$ & $t_{19}=0.6$ & $t_{19}=-0.9$ & $t_{19}=0.5$ \\
\hline \multirow[t]{3}{*}{23} & 2 and 3 & -7.0 & 6.7 & 10.5 & -17.2 \\
\hline & & $P=.025^{*}$ & $P=.175$ & $P=.216$ & $P=.074$ \\
\hline & & $t_{22}=-2.4$ & $t_{22}=1.4$ & $t_{22}=1.3$ & $t_{22}=-1.9$ \\
\hline \multicolumn{6}{|c|}{$50 \%$ BW target load } \\
\hline \multirow[t]{3}{*}{8} & 1 and 2 & -3.17 & -1.9 & 0.1 & 1.8 \\
\hline & & $P=.409$ & $P=.686$ & $P=.977$ & $P=.538$ \\
\hline & & $t_{7}=0.9$ & $t_{7}=0.4$ & $t_{7}=-0.0$ & $t_{7}=-0.6$ \\
\hline \multirow[t]{3}{*}{10} & 2 and 3 & -11.5 & 30.3 & -21.0 & -9.4 \\
\hline & & $P=.027^{*}$ & $P=.041^{*}$ & $P=.116$ & $P=.043^{*}$ \\
\hline & & $t_{9}=-2.6$ & $t_{9}=2.4$ & $t_{9}=-1.7$ & $t_{9}=-2.4$ \\
\hline
\end{tabular}

NOTE. Values are mean difference $(\Delta)$. Body weight ranges: $10 \%$ target load: "below target $(<\mathrm{TL})$ " $=0 \%-5 \%$ BW; "equal to target $(=\mathrm{TL}) "=5 \%-20 \%$ BW; "above target $(>\mathrm{TL}) "=20 \%-100 \%$ BW; $50 \%$ target load: " $<\mathrm{TL}$ " $=0 \%-40 \%$ BW; " $=\mathrm{TL}$ " $=40 \%-60 \%$ BW; ">TL" $=60 \%-100 \%$ BW

* Significant at $P<.05$.

operated leg more weight has to be placed on the walking aid, and, therefore, more muscle strength of the upper arm is needed. ${ }^{29,30}$ Chow et $\mathrm{al}^{31}$ found that the muscle power of the upper arm influenced the ability of the patient to perform PWB. Higher weight-bearing loads (up to $90 \%-95 \%$ BW) were measured in the $50 \% \mathrm{BW}$ target load group, which could increase the risk of complications. Therefore, a simple practical solution to decrease weight bearing in the $50 \%$ BW target load group could be to use the more strict $10 \% \mathrm{BW}$ weight-bearing verbal instructions. For instructing patients at a $10 \% \mathrm{BW}$ target load, other methods (eg, audio feedback) should be used. ${ }^{5,7,32}$

To evaluate PWB, it is important to measure not only the amount of loading but also the duration (amount of steps) of loading. Complications can occur because of an occasional full weight bearing but may also occur as a result of long-term weight bearing just above the target load. Individual patient data in our study show a large variability in amount and duration of loading between separate walking periods, ranging from several seconds to 10 to 20 minutes. Also, an increase in loading was seen in the longer walking periods, which may indicate that patients were getting (more) fatigued because of longer intensive use of the walking aids and/or were becoming less concentrated. ${ }^{18,26-28}$ This suggests that weight-bearing instructions should not only include a restriction in the amount of loading but also emphasize the importance of limiting the duration of walking to, for instance, 5-minute walking sessions.

\section{Study Limitations}

There is still no definition or consensus as to what constitutes "too much" loading because no data are available that relate complication rates to either the amount or the duration of loading. Therefore, the surgeons in our hospital use the arbitrarily chosen weight-bearing cutoffs (below, equal, above) for the $10 \%$ and $50 \%$ BW target load as described in the methods and considered $10 \%$ (or less) of the steps above the target load to be acceptable. The 2 target load groups were not compared on the outcome measures because of differences in size and patient characteristics. PWB differences between the 2 target load groups could also be caused by confounding elements such as different physical therapists at the 2 hospitals. The statistical analysis used in our study (ie, repeated $t$ tests) has its limitations. Other statistical methods (eg, repeated-measures analysis, Bonferroni adjustment) were considered; however, these methods also have their restrictions. The data in the article do not suggest that some results were statistically significant by chance, for example, 5 of the 6 one-sample $t$ tests were significant instead of 1 comparison $(5 \% \times 6$ tests $=0.3)$ was falsely declared significant at $P$ less than .05 . Furthermore, given the sample sizes in our study we chose to use standard $t$ tests.

\section{CONCLUSIONS}

PWB at a specific target load was not achieved by patients with a THA when given verbal instructions. Especially when using a low target load and when walking at home with no supervision of a physical therapist, patients loaded the operated leg higher and more frequently above the target load. When a $50 \%$ target load is prescribed, verbal instructions for $10 \%$ target load training could be used to avoid high weight-bearing loads at the patient's home. However, other training methods (eg, biofeedback), have to be evaluated for being useful training tools for PWB at specific target loads. Also, little to no information is available on the influence of factors (eg, age, body weight, upper-extremity force, duration of walking) on the amount of loading during weight bearing. This information is important for the clinician to properly instruct patients to perform PWB in the hospital and especially during recovery at home.

\section{References}

1. Vasarhelyi A, Baumert T, Fritsch C, Hopfenmüller W, Gradl G, Mittlmeier T. Partial weight bearing after surgery for fractures of the lower extremity-is it achievable? Gait Posture 2006;23:99105 .

2. Chow DH, Cheng CT. Quantitative analysis of the effects of audio biofeedback on weight-bearing characteristics of persons with transtibial amputation during early prosthetic ambulation. J Rehabil Res Dev 2000;37:255-60. 
3. Endicott D, Roemer R, Brooks S, Meisel H. Leg load warning system for the orthopaedically handicapped. Med Biol Eng 1974; 12:318-21.

4. Gapsis JJ, Grabois M, Borrell RM, Menken SA, Kelly M. Limb load monitor: evaluation of a sensory feedback device for controlled weight bearing. Arch Phys Med Rehabil 1982;63:38-41.

5. Perren T, Matter P. [Feedback-controlled weight bearing following osteosynthesis of the lower extremity] [German]. Swiss Surg 1996;2:252-8.

6. Phillips TW, Nguyen LT, Munro SD. Loosening of cementless femoral stems: a biomechanical analysis of immediate fixation with loading vertical, femur horizontal. J Biomech 1991;24:37-48.

7. Siebert WE. Partial weight bearing after total hip arthroplasty. What does the patient really do? A prospective randomized gait analysis. Hip Int 1994;4:61-8.

8. Tveit M, Kärrholm J. Low effectiveness of prescribed partial weight bearing. Continuous recording of vertical loads using a new pressure-sensitive insole. J Rehabil Med 2001;33:42-6.

9. Weaver JK. Total hip replacement: a comparison between the transtrochanteric and posterior surgical approaches. Clin Orthop Relat Res 1975;Oct(112):201-7.

10. Wirtz DC, Heller KD, Niethard FU. [Biomechanical aspects of load-bearing capacity after total endoprosthesis replacement of the hip joint. An evaluation of current knowledge and review of the literature] [German]. Z Orthop Ihre Grenzgeb 1998;136:310-6.

11. Teanby DN, Monsell FP, Goel R, Faux JC, Hardy SK. Failure of trochanteric osteotomy in total hip replacement: a comparison of two methods of reattachment. Ann R Coll Surg Engl 1996;78: 43-4.

12. Frankel A, Booth RE Jr, Balderston RA, Cohn J, Rothman RH. Complications of trochanteric osteotomy. Long-term implications. Clin Orthop Relat Res 1993;Mar(288):209-13.

13. Glassman AH. Complications of trochanteric osteotomy. Orthop Clin North Am 1992;23:321-33.

14. Clarke RP Jr, Shea WD, Bierbaum BE. Trochanteric osteotomy: analysis of pattern of wire fixation failure and complications. Clin Orthop Relat Res 1979;Jun(141):102-10.

15. Burdet A, Taillard W, Blanc Y. [Standing and walking with walking aids - an electromyokinesigraphic examination] [German]. Z Orthop Ihre Grenzgeb 1979;117:247-59.

16. Volz RG, Brown FW. The painful migrated ununited greater trochanter in total hip replacement. J Bone Joint Surg Am 1977; 59:1091-3.

17. Gray FB, Gray C, McClanahan JW. Assessing the accuracy of partial weight-bearing instruction. Am J Orthop 1998;27:558-60.

18. Wright DL, Kemp TL. The dual-task methodology and assessing the attentional demands of ambulation with walking devices. Phys Ther 1992;72:306-12.
19. Li S, Armstrong CW, Cipriani D. Three-point gait crutch walking: variability in ground reaction force during weight bearing. Arch Phys Med Rehabil 2001;82:86-92; discussion 313-5.

20. Warren CG, Lehmann JF. Training procedures and biofeedback methods to achieve controlled partial weight bearing: an assessment. Arch Phys Med Rehabil 1975;56:449-55.

21. Baxter ML, Allington RO, Koepke GH. Weight-distribution variables in the use of crutches and canes. Phys Ther 1969;49:360-5.

22. Hurkmans HL, Bussmann JB, Selles RW, et al. Validity of the Pedar Mobile system for vertical force measurement during a seven-hour period. J Biomech 2006;39:110-8.

23. Hurkmans HL, Bussmann JB, Benda E, Verhaar JA, Stam HJ. Accuracy and repeatability of the Pedar Mobile system in longterm vertical force measurements. Gait Posture 2006;23:118-25.

24. Winstein CJ, Pohl PS, Cardinale C, Green A, Scholtz L, Waters CS. Learning a partial-weight-bearing skill: effectiveness of two forms of feedback [published erratum in: Phys Ther 1997;77:328]. Phys Ther 1996;76:985-93.

25. Koval KJ, Sala DA, Kummer FJ, Zuckerman JD. Postoperative weight-bearing after a fracture of the femoral neck or an intertrochanteric fracture. J Bone Joint Surg Am 1998;80:352-6.

26. Foley MP, Prax B, Crowell R, Boone T. Effects of assistive devices on cardiorespiratory demands in older adults. Phys Ther 1996;76:1313-9.

27. Hall J, Elvins DM, Burke SJ, Ring EF, Clarke AK. Heart rate evaluation of axillary and elbow crutches. J Med Eng Technol $1991 ; 15: 232-8$

28. Fisher SV, Patterson RP. Energy cost of ambulation with crutches. Arch Phys Med Rehabil 1981;62:250-6.

29. Crosbie J. Muscle activation patterns in aided gait. Clin Rehabil 1993;7:229-38

30. Opila KA, Nicol AC, Paul JP. Upper limb loadings of gait with crutches. J Biomech Eng 1987;109:285-90.

31. Chow SP, Cheng CL, Hui PW, Pun WK, Ng C. Partial weight bearing after operations for hip fractures in elderly patients. J R Coll Surg Edinb 1992;37:261-2.

32. Schon LC, Short KW, Parks BG, Kleeman TJ, Mroczek K. Efficacy of a new pressure-sensitive alarm for clinical use in orthopaedics. Clin Orthop Relat Res 2004;Jun(423):235-9.

\section{Suppliers}

a. Novel Gmbh, Ismaninger St 51, 81675 Munich, Germany.

b. Greisinger Electronic GmbH, Hans-Sachs-Str 26, D-93128 Regenstauf, Germany.

c. The MathWorks Inc, 3 Apple Hill Dr, Natick, MA 01760-2098.

d. Version 10; SPSS Inc, $233 \mathrm{~S}$ Wacker Dr, 11th Fl, Chicago, IL 60606. 